\title{
CAPP MODEL OF FUZZY SYSTEMS AND FUZZY MANUFACTURABILITY
}

\author{
Mr. Radivoje Antic VSPSS 17501 in Vranje, Serbia, radeantic@ open.telekom.rs, tel 023/421859, \\ Slavica Cvetkovic, Faculty of Technical Sciences, Kosovska Mitrovica 38 220, Serbia, \\ smijoc@yahoo.com, \\ Branko Pejovic, Faculty of Technical Sciences, Kosovska Mitrovica 38 220, Serbia, offfice@ ftnkm.rs, \\ tel.028/425320 \\ Milan Cvetkovic, PMF Nis, Serbija.
}

\begin{abstract}
They give the soles of technological design process using fuzzy logic for metal cutting, referring to the determination of all the elements of production process: the dimensions and quality of the workpiece material, the sequence and scope of operations, the order and content of the procedures, the size of the type of machine types and tool types and gauges, regime and time of processing. It further explains manufacturability machine parts for robust design of a new product. He also offers manufacturability for cylindrical, prismatic workpieces and boxes. It explains the mathematical expressions of fuzzy logic which described above manufacturability. In fuzzy logic are used mathematical operations minimization and maximization. They are used to determine the critical solutions and choice of cost effective solutions. Provides an example of using the model to determine of the manufacturability.
\end{abstract}

Key words: Fuzzy logic, manufacturability of machine parts, metal cutting, production processes, design of technological processes, workprace design.

\section{INTRODUCTION}

Previous research in the world and in our FUZZYCAPP system are applied to minimize input and output variables and maximizing results of the elements of production process (TPO). Fuzzy models for the functioning FUZZYCAPP systems from practical aspects did not exist.

In the design of the technological processes (TP), and pieces of work (WR) is one of the problems is their small manufacturability.

Reviewing manufacturability in practice will be achieved by pointing to the bad solutions: size, accuracy, operation, materials, tools and cutting speeds WR. It will be solved using the minimum values of fuzzy variable input output elements of TP.

\subsection{BASICS OF FUZZY CAPP}

The goal of this research is to develop FUZZYCAPP system of metal by cutting (OMR), with the development of software which confirms the results of that were obtained in the study. During research into will use criteria for of minimum values of values influencing elements TPO and their maximum values of results using fuzzy logic.

The research will define in details the fuzzy models for the input and output of fuzzy variables TPO, shown on flowchart numbers

Fuzzy models listed input and output variables TPO have a basic function to define their degree of belonging to the fuzzy variables.

FUZZYCAPP system takes oversize of WR and creating elements TPO with six modules: the choice of workpiece, setting operations, selection of machines and other workplaces, determining procedures, the determination cutting tools and measuring measures determination of cutting data and machine processing times. 
First is the determined by dimension and the shape of workpiece with the obtained characteristics of WR. In modulo "Measures workpiece" program searches of fuzzy rules BK - workpiece to form WR and finds the corresponding. With his instructions, selects additions for the processing from BD and dimensions of values determined by computational workpiece. With other hand, the the appropriate dimensions, tolerances, machined surface roughness and materials WR the driver from corresponding of fuzzy the model defines the values of the input and output size workpiece. On the basis of calculating set-point workpiece program selects of his standard value of BD.

After the selection of are determined the operation workpiece. In modulo "Determining of operations" program defines a sequence of operations based on her of fuzzy rules from $\mathrm{BK} \mathrm{i}$ according to the material, dimensions, tolerances and machined surface roughness WR, that represents of fuzzy variables. With the listed of fuzzy the variables, adding variables operations from the respective of fuzzy models, the same program determines the values of its input and output values.

Following is a selection of machines and other jobs. In modulo "Defining machines" program selects the type and size of the machine and in the other jobs - their name is used: BD and their of fuzzy rules from BK, certain operations from the previous module and the WR Dimensions of technological form of CAD systems. In the module "Determination procedure "program determines procedures, using their: BD Text and fuzzy rules from the $\mathrm{BK}$, operations defined by the in the preceding module and dimensions of WR - CAD system. In determining of the cutting tools and measuring instruments are used a fuzzy the rules BK. The program determines cutting tools and measuring instruments by using their $\mathrm{BP}$ and fuzzy models, the procedure defined in the previous module and dimensions of technology WR form of CAD systems.

Determination of basic the cutting regime and time is realized in the module "the cutting regime" their fuzzy rules BK. Used: BP machine dimensions of technological forms, WR of CAD system with its fuzzy values and cutting speed of her fuzzy models.

\subsubsection{Manufacturability diameters and lengths of cylindrical WR $\left(\mu_{\text {cd }}\right)$}

Membership functions for manufacturability - diameters processing form or PR are processed in [Antic 2012a and oth.]. Profitable lengths for small machines are 100 - 200 $\mathrm{mm}$, for medium machine $300-650 \mathrm{~mm}$ well as in larger 750 - 3900mm, shown in Fig. 1

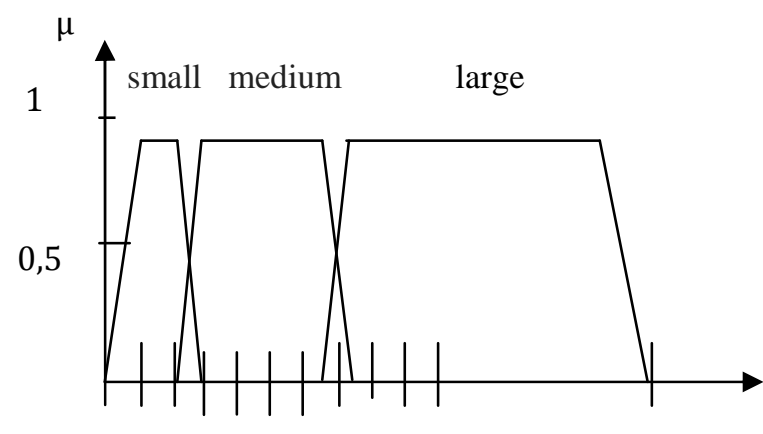

$0 \quad 200 \quad 400600 \quad 8001000$

$4000 \mathrm{~L}$ (mm)

Figure 1. Membership functions for special manufacturability - the length of time, form or WR small width

In 3 domain of expressions (1.1) - (1.4).

$\mathrm{L}$ (length) $=\{$ short length, medium length, large length $\}=\{\mathrm{ML}, \mathrm{SL}, \mathrm{VL}\}$

$\mu_{\mathrm{ML}}(\mathrm{L})=\left\{\begin{array}{cc}\mathrm{L} / 100 ; & 0 \leq \mathrm{L}<100 \\ 1 ; & 100 \leq \mathrm{L}<200 \\ -\mathrm{L} / 100+3 ; & 200 \leq \mathrm{L}<300\end{array}\right\}$

$\left.\mu_{\mathrm{SL}}(\mathrm{L})=\left\{\begin{array}{cc}\mathrm{L} / 100-2 ; & 200 \leq \mathrm{L}<300 \\ 1 ; & 300 \leq \mathrm{L}<650 \\ -\mathrm{L} / 100+7,5 ; 650 \leq \mathrm{L}<750\end{array}\right\} 1.3\right)$

$\mu_{\mathrm{VL}}(\mathrm{L})=\left\{\begin{array}{l}\mathrm{L} / 100-6,5 ; \\ 1 ; \quad 650 \leq \mathrm{L}<750 \\ \mathrm{~L} / 100+40 ; 3900 \leq \mathrm{L} \leq 4000\end{array}\right\}(1.4)$ 


\subsubsection{Manufacturability Cheese - the height and length of prismatic WR $\left(\mu_{\mathrm{pd}}\right)$}

Membership functions for manufacturability width processing form or WR is dealt with in [Antic 2012a and oth.].

Profitably length for small machines are 50 $250 \mathrm{~mm}$, for medium $300-450 \mathrm{~mm}$ in large 500 - 950mm, shown in Fig. 2, whose expressions are (1.5) - (1.8).

Lengths forms of technology and WR are grouped into 3 domains. For the length we have the following labels:
L (length) $=\{$ short length, medium length, great length $\}=\{\mathrm{ML}, \mathrm{SL}, \mathrm{VL}$

$$
\text { (1.5) }
$$

$\mu_{\mathrm{ML}}(\mathrm{L})=\left\{\begin{array}{cc}\mathrm{L} / 50 ; & 0 \leq \mathrm{L}<50 \\ 1 ; & 50 \leq \mathrm{L}<250 \\ -\mathrm{L} / 50+6 ; 250 \leq \mathrm{L} \leq 300\end{array}\right\}(1.6)$

$$
\begin{aligned}
& \mu_{\mathrm{SL}}(\mathrm{L})=\left\{\begin{array}{cc}
\mathrm{L} / 50-5 ; & 250 \leq \mathrm{L}<300 \\
1 ; & 300 \leq \mathrm{L}<450 \\
-\mathrm{L} / 50+10 ; 450 \leq \mathrm{L} \leq 500
\end{array}\right\} \\
& \mu_{\mathrm{VL}}(\mathrm{L})=\left\{\begin{array}{c}
\mathrm{L} / 50-9 ; 450 \leq \mathrm{L}<500 \\
1 \quad ; 500 \leq \mathrm{L}<950 \\
-\mathrm{L} / 50+20 ; 950<\mathrm{L} \leq 1000
\end{array}\right\}
\end{aligned}
$$

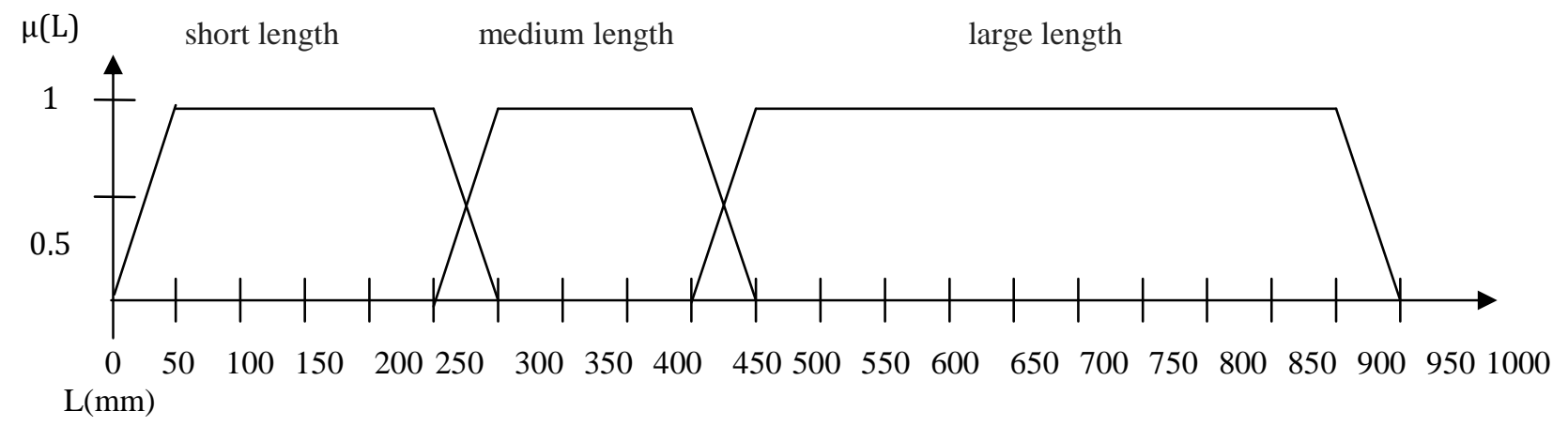

Figure 2 Function belonging to a special manufacturability - the length of time of prismatic form or WR

\subsubsection{Manufacturability width - height and length of box section WR $\left(\mu_{\mathrm{kd}}\right)$}

For width - height and length of boxWR are given their sizes while processing your on vertical or milling machines and grinding machines for flat grinding. Provide data to partitions machines in practice into three groups - small, medium and large. Profitable width and height of small machines are $200-400 \mathrm{~mm}$, with the mean 600 $800 \mathrm{~mm}$ and in major $1000-1400 \mathrm{~mm}$.

Width and height of technology forms and WR are grouped into 3 domains and machines as shown in Fig. 3, whose expressions are (1.9) - (2.2).

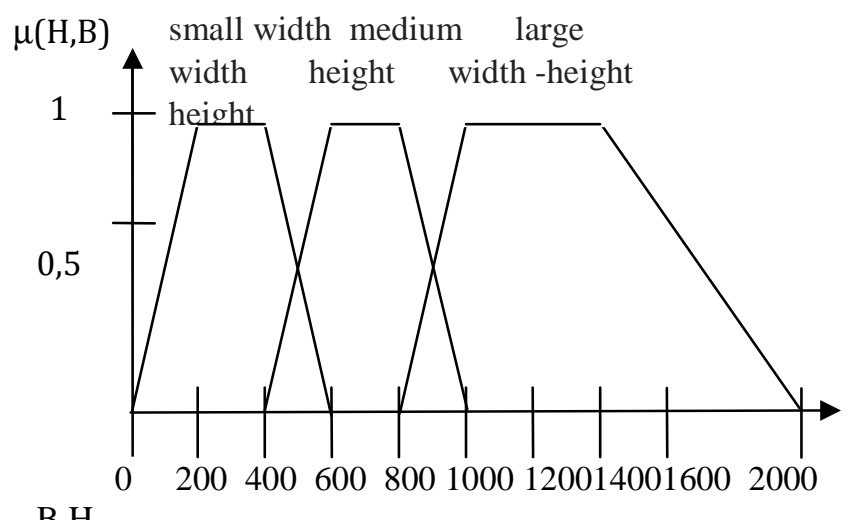

B, $\mathrm{H}$

Figure 3 manufacturability membership function of the width (height) - processing forms a box - like parts (mm) 
Width - the height and length of the technological form and WR are grouped into 3 domains.

B - $(\mathrm{H})$ (width - height $)=\{$ small width, height, medium width. height, large width height $\}=\{$ VG - MV, SS - SV, Sun - VV $\}$ (1.9)

$$
\mu_{\mathrm{MS} \div \mathrm{MV}}(\check{\mathrm{S}} \div \mathrm{V})=\left\{\begin{array}{cc}
\mathrm{S} \div \mathrm{V} / 200 ; & 0 \leq \mathrm{S} \div \mathrm{V}<200 \\
1 ; & 200 \leq \mathrm{S} \div \mathrm{V}<400 \\
-\mathrm{S} \div \mathrm{V} / 200+3 ; 400 \leq \mathrm{S} \div \mathrm{V}<600
\end{array}\right\}(2.0)
$$

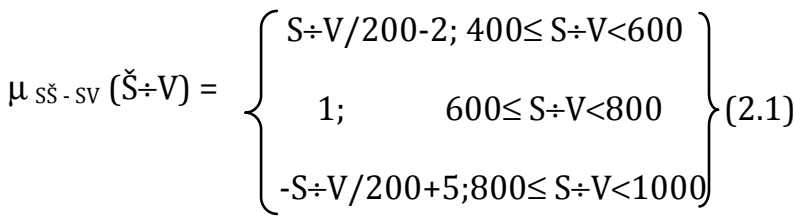

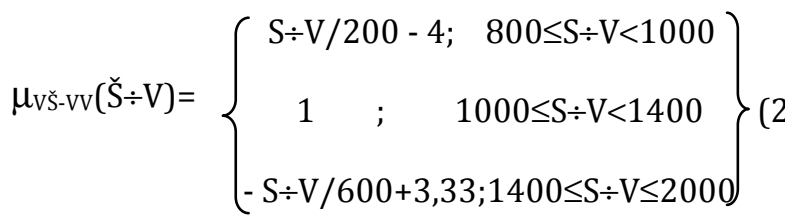

Profitable length of box-like of parts for small machines are $200-400 \mathrm{~mm}$, for medium machines are $600-800 \mathrm{~mm}$ with are big 1000 $1800 \mathrm{~mm}$, shown in Fig. 4, whose terms are (2.3)-(2.6).

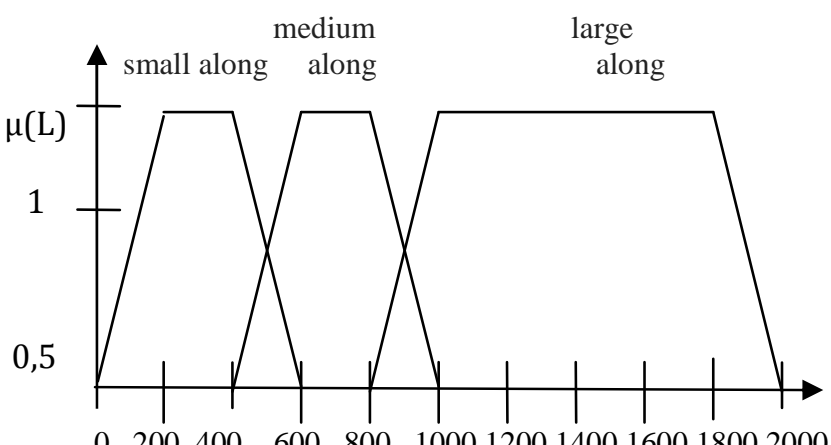

$0 \quad 200400 \quad 600 \quad 800 \quad 100012001400160018002000$

Figure 4 membership function for a special $\mathrm{L}(\mathrm{mm})$ manufacturability length of time box-WR or form tehnologičnost dužine obrade kutijastih PR ili forme

Are valid for the length depending on of the following labels:

$\mathrm{L}$ (length) $=\{$ small along., Medium along., Along great. $\}=\{\mathrm{ML}, \mathrm{SL}, \mathrm{VL}\}$

$$
\mu_{\mathrm{ML}}(\mathrm{L})=\left\{\begin{array}{cc}
(\mathrm{L}) / 200 ; & 0 \leq(\mathrm{L})<200 \\
1 ; & 200 \leq(\mathrm{L})<400 \\
-(\mathrm{L}) / 200+3 ; & 400 \leq(\mathrm{L})<600
\end{array}\right\}
$$

$$
\mu_{\mathrm{SL}}(\mathrm{L})=\left\{\begin{array}{cc}
(\mathrm{L}) / 200-2 ; & 400 \leq(\mathrm{L})<600 \\
1 ; & 600 \leq(\mathrm{L})<800 \\
(\mathrm{~L}) / 200+5 ; & 800 \leq(\mathrm{L})<100
\end{array}\right\}
$$

$\mu_{\mathrm{VL}}(\mathrm{L})=\left\{\begin{array}{cc}\mathrm{L} / 200-4 ; & 800 \leq \mathrm{L}<1000 \\ 1 ; & 1000 \leq \mathrm{L} \leq 1800 \\ -\mathrm{L} / 200+10 ; & 1800 \leq \mathrm{L} \leq 2000\end{array}\right\}$

\subsection{5 manufacturability length and diameter of ancillary holes $\left(\mu_{\text {by }}\right)$}

Length and diameters of ancillary holes are provided according groups of drill.

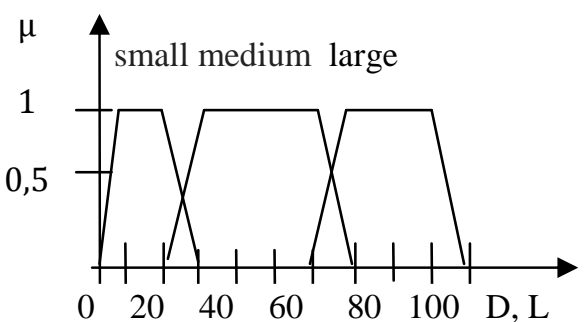

Figure 5. Determining the origin of manufacturability length and diameter, hole processing, forms or WP on the drill

Profitable length and hole diameter for small machines are $10-20 \mathrm{~mm}$ in medium 30 $60 \mathrm{~mm}$ in large $70-90 \mathrm{~mm}$, shown in Fig. 5, whose are expressions of (2.7) - (3.0).

For the length and diameter of the auxiliary openings are valid according to the following labels:

$\mathrm{L}, \mathrm{D}$ (length, diameter $)=\{$ small length, diameter small, medium length, medium diameter, and the large length, large diameter $=\{\mathrm{ML}, \mathrm{MD} ; \mathrm{SL}, \mathrm{SD} ; \mathrm{VL}, \mathrm{VD}\}$ 


$$
\begin{gathered}
\mu_{\mathrm{ML}, \mathrm{MD}}(\mathrm{L}, \mathrm{D})=\left\{\begin{array}{cc}
(\mathrm{L}, \mathrm{D}) / 10 ; & 0 \leq(\mathrm{L}, \mathrm{D})<10 \\
1 ; & 10 \leq(\mathrm{L}, \mathrm{D})<20 \\
(\mathrm{~L}, \mathrm{D}) / 10+3 ; 20 \leq(\mathrm{L}, \mathrm{D})<30
\end{array}\right\}(2.8) \\
\mu_{\mathrm{SL}}(\mathrm{L}, \mathrm{D})=\left\{\begin{array}{cc}
(\mathrm{L}, \mathrm{D}) / 10-2 ; & 20 \leq(\mathrm{L}, \mathrm{D})<30 \\
1 ; & 30 \leq(\mathrm{L}, \mathrm{D})<60 \\
(\mathrm{~L}, \mathrm{D}) / 10+7 ; 60 \leq(\mathrm{L}, \mathrm{D})<70
\end{array}\right\}(2.9) \\
\mu_{\mathrm{VL}}(\mathrm{L}, \mathrm{D})=\left\{\begin{array}{cc}
(\mathrm{L}, \mathrm{D}) / 10-6 ; 60 \leq(\mathrm{L}, \mathrm{D})<70 \\
1 \quad 70 \leq(\mathrm{L}, \mathrm{D}) \leq 90 \\
-(\mathrm{L}, \mathrm{D}) / 10+10 ; 90 \leq(\mathrm{L}, \mathrm{D}) \leq 100
\end{array}\right\}(3.0)
\end{gathered}
$$

\subsubsection{Membership function width - height and length of box-WR}

For width - height and length of boxWR are given to their size when processing to vertical milling machines and grinding machines for flat grinding. Data is given to partitions machine in practice into three groups - small, medium and large. Profitable the width and height of small machines are 200 $400 \mathrm{~mm}$, for the mean $600-800 \mathrm{~mm}$ in large 1000

$1400 \mathrm{~mm}$.

Width and height of technology forms and WR are grouped into 3 domains and machines as shown in Fig. 6, whose expresses the (3.1) (3.4).

small width medium large width

(B) height width - height height

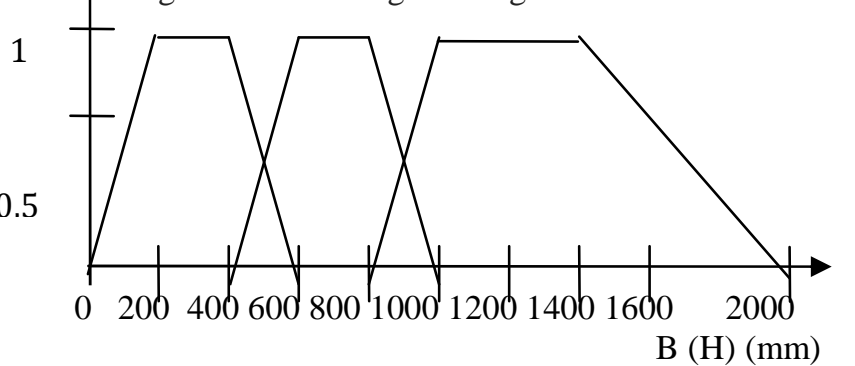

Figure 6. Membership functions of width (height) box-like forms of processing components

Width - the height and the length of technological form and WR are grouped into 3 domains.

B $-(H)($ width - height $)=\{$ small width, height, medium width. height, large width height $\}=\{$ VG - MV, SS - SV, SV - VV \}

$$
\begin{aligned}
& \mu_{S \check{S}-\mathrm{SV}(\check{S} \div \mathrm{V})}=\left\{\begin{array}{cc}
\mathrm{S} \div \mathrm{V} / 200 & -2 ; 400 \leq \mathrm{S} \div \mathrm{V}<600 \\
1 ; & 600 \leq \mathrm{S} \div \mathrm{V}<800 \\
-\mathrm{S} \div \mathrm{V} / 200+5 ; 800 \leq \mathrm{S} \div \mathrm{V}<1000
\end{array}\right\}(3.3)
\end{aligned}
$$

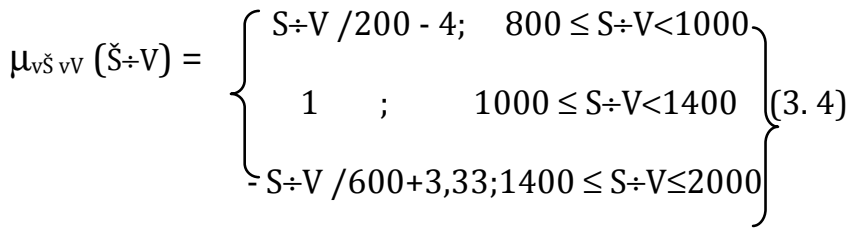

Profitable long box-profitable parts for small machines are $200-400 \mathrm{~mm}$, with medium-sized machines are $600-800 \mathrm{~mm}$ with the large $1000-1800 \mathrm{~mm}$, as shown in Fig. 7, which are expressions of (3.5) - (3.8). Are valid for the length depending of the following labels: $\mathrm{L}$ (length) $=\{$ small along., Medium along., Along great. $\}=\{\mathrm{ML}, \mathrm{SL}, \mathrm{VL}\}$

$$
\begin{gathered}
\mu_{\mathrm{ML}}(\mathrm{L})=\left\{\begin{array}{cr}
(\mathrm{L}) / 200 ; & 0 \leq(\mathrm{L})<200 \\
1 ; & 200 \leq(\mathrm{L})<400 \\
-(\mathrm{L}) / 200+3 ; & 400 \leq(\mathrm{L})<600
\end{array}\right\}(3.6) \\
\mu_{\mathrm{SL}}(\mathrm{L})=\left\{\begin{array}{cc}
(\mathrm{L}) / 200-2 ; & 400 \leq(\mathrm{L})<600 \\
1 ; & 600 \leq(\mathrm{L})<800 \\
-(\mathrm{L}) / 200+5 ; & 800 \leq(\mathrm{L})<100
\end{array}\right\}(3.7) \\
\mu_{\mathrm{VL}}(\mathrm{L})=\left\{\begin{array}{c}
\mathrm{L} / 200-4 ; 800 \leq \mathrm{L}<1000 \\
1 \quad ; 1000 \leq \mathrm{L} \leq 1800 \\
-\mathrm{L} / 200+10 ; 1800 \leq \mathrm{L} \leq 2000
\end{array}\right\}(3.8)
\end{gathered}
$$

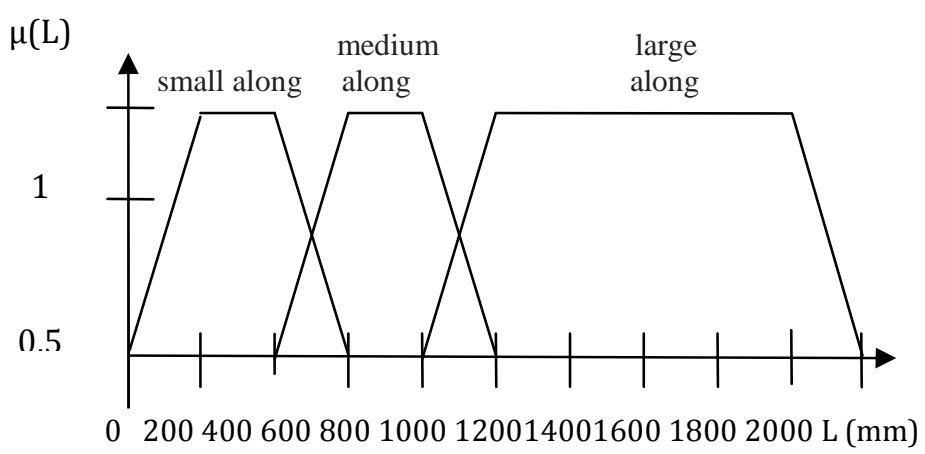

Figure 7. Membership functions of the length of time box-WR or form 


\subsubsection{Membership function of length and diameter of ancillary holes}

The lengths and diameters of auxiliary holes are provided to groups of drill.

Profitable length and hole diameter of small machines are $10-20 \mathrm{~mm}$ for medium 30 - 60mm in large $70-90 \mathrm{~mm}$, as shown in Fig. 8, which are expressions of (3.9) - (3.12).

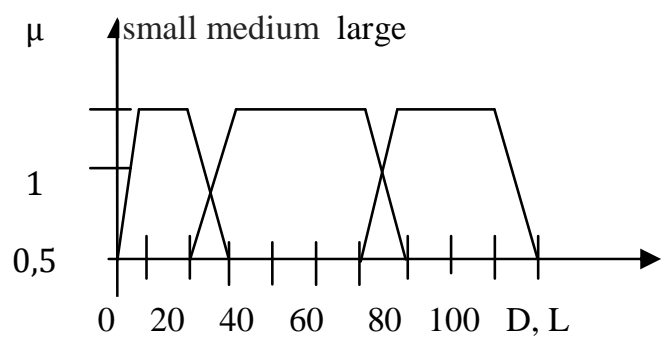

Sl. 8. Determining the degree of membership of the length and diameter of the hole processing, form WR to drill

For the length and diameter of the auxiliary openings are valid according to the following labels:

L, D (length, diameter) $=\{$ short length, prčnik small, medium length, medium diameter, and the large length, large diameter $\}=\{\mathrm{ML}$, MD; SL, SD; VL, VD \}

$\mu_{\mathrm{ML}, \mathrm{MD}}(\mathrm{L}, \mathrm{D})=\left\{\begin{array}{cc}(\mathrm{L}, \mathrm{D}) / 10 ; & 0 \leq(\mathrm{L}, \mathrm{D})<10 \\ 1 ; & 10 \leq(\mathrm{L}, \mathrm{D})<20 \\ -(\mathrm{L}, \mathrm{D}) / 10+3 ; 20 \leq(\mathrm{L}, \mathrm{D})<30\end{array}\right\}(3.10)$ $\mu_{\mathrm{SL}}(\mathrm{L}, \mathrm{D})=\left\{\begin{array}{c}(\mathrm{L}, \mathrm{D}) / 10-2 ; 20 \leq(\mathrm{L}, \mathrm{D})<30 \\ 1 ; \\ -(\mathrm{L}, \mathrm{D}) / 10+7 ; 60 \leq(\mathrm{L}, \mathrm{D})<70\end{array}\right\}$ (3. 11) $\mu_{\mathrm{VL}}(\mathrm{L}, \mathrm{D})=\left\{\begin{array}{cc}(\mathrm{L}, \mathrm{D}) / 10-6 ; & 60 \leq(\mathrm{L}, \mathrm{D})<70 \\ 1 \quad ; & 70 \leq(\mathrm{L}, \mathrm{D}) \leq 90 \\ -(\mathrm{L}, \mathrm{D}) / 10+10 ; 90 \leq(\mathrm{L}, \mathrm{D}) \leq 100\end{array}\right\}(3.12)$

\subsubsection{Manufacturability materials for working cases $\left(\mu_{\mathrm{m}}\right)$}

Membership functions for manufacturability - WR of materials dealt with in [Antic 2012b and oth.].

\subsubsection{Manufacturability for accuracy $\left(\mu_{t}\right)$}

Membership functions for special manufacturability - wide processing form or PR is dealt with in [Antic2012b and oth.].

\section{THE RESULTS OF THE APLLICATION OF FUZZY CAPP AND MANUFACTURABILITY}

Fuzzy CAPP system and fuzzy manufacturability were tested and the following results [Antic 2012a, 2013]. It has been tested for prismatic of workpiece machining conditions favorable for the design of technological processes using fuzzy CAPP system, and obtained the degree of fuzzy membership of functions $\mu=0.75$. This means that the medium very good workability. When testing manufacturabilit same example performed improving design of workpieces by the aggregate value of manufacturabilit of drawings below 0.5 designers coming back to improvement. 
(JPMNT) Journal of Process Management - New Technologies, International

Vol. 1, No.4, 2013.

\section{CONCLUSION}

Using fuzzy of logic for CAPP system, and manufacturabilit improves the design of work objects and their technological processes according to a given results.

\section{REFERENCES}

[1] Radivoje Antic, Mirko Djapic Dragan Lukic, Application of the parts logistic design process planning with the FUZZYCAPP metal processing by cutting metal processing by cuting, METALURGIA INTERNATIONAL, Vol 17, No. 7-2012, 79-86, ISSN 1582-2214. [2] Radivoje Antic, Mirko Djapić, Ljubomir Lukic, Improvement of the characteristcs of CAD system, working metal cutting, using fuzzy logistic designproducts of workpiece, METALURGIA INTERNATIONAL, Vol 17, No. 12-2012, 39-43, ISSN

1582-2214.

[3] Radivoje Antic, Slavica Cvetkovic, Milan Cvetkovic, Defining of manufacturability manufacturing proceses - metal cuting by fuzzy logic for disign product, METALURGIA INTERNATIONAL, 2013 ISSN 1582-2214 